\title{
Flexible Endoscopic Spray Application of Respiratory Epithelial Cells as Platform Technology to Apply Cells in Tubular Organs
}

\author{
Anja Lena Thiebes, MSc, Manuel Armin Reddemann, Dr-Ing,2 Johannes Palmer, Dipl-Ing Dipl-Wirt Ing, \\ Reinhold Kneer, Univ-Prof Dr-Ing,2 Stefan Jockenhoevel, Univ-Prof Dr Med, \\ and Christian Gabriel Cornelissen, Dr Med ${ }^{1,4}$
}

Introduction: Inoperable airway stenoses are currently treated by placing stents. A major problem of covered stents is missing mucociliary clearance, which is caused by covering the native respiratory epithelium. By coating a stent with respiratory epithelium, this problem can be overcome. However, no methods are available for efficient endoscopic cell seeding.

Methods: We designed a flexible endoscopic spraying device based on a bronchoscope and tested it with respiratory epithelial cells. With this device cells can also be applied in a thin layer of fibrin glue. We evaluated the survival rate directly after spray application with a live-dead staining and the long-term differentiation capacity with histology and electron microscopy. Furthermore, the random distribution of cells when applied in a tube was analyzed and the macroscopic and microscopic characteristics of the endoscopic spray were investigated using high-speed visualization.

Results: Spray visualization revealed a polydisperse character of the spray with the majority of droplets larger than epithelial cells. Spray application does not influence the survival rate and differentiation of respiratory epithelial cells. After 4 weeks, cells built up a pseudostratified epithelial layer with cilia and goblet cells. When cells are applied in a thin layer of fibrin gel into a tube, a nearest neighbor index of 1.2 is obtained, which suggests a random distribution of the cells.

Conclusions: This spraying device is a promising tool for application of various cell types onto stents or implants with high survival rates and homogeneous distribution as shown in this study for ovine respiratory epithelial cells. The system could also be used for cell therapy to locally apply cells to the diseased parts of hollow organs. For the first time, the fluid dynamics of a spray device for cells were examined to validate in vitro results.

\section{Introduction}

A IRWAY OBSTRUCTION CAN be caused by various pathologies, for example, carcinoma, trauma, or infection. ${ }^{1}$ Remaining untreated, complete airway obstruction might be imminent. When surgical treatment is not an option for the patient, stenting is the palliative treatment of choice. Silicone stents are currently the gold standard for most diseases. Still, they have serious disadvantages as a high migration risk and mucostasis, which occurs in about $30 \%$ of patients. ${ }^{2}$ Bare-metal stents might offer an alternative as they have a lower migration risk, but they are not suitable for malignant stenoses as they do not prevent tumor ingrowth. ${ }^{3}$

Thus, as new method for palliative treatment of patients with malignant airway stenosis we developed the PulmoStent concept, based on the vascular BioStent, ${ }^{4,5}$ as shown in Figure 1. When combining a covered metal stent with a tissue engineered epithelial lining, mucostasis and the migration risk can be overcome. For implantation of stents, they have to be crimped to a small diameter. Respiratory epithelial cells are

\footnotetext{
${ }^{1}$ Department of Tissue Engineering and Textile Implants, Institute of Applied Medical Engineering, Helmholtz Institute, RWTH Aachen University, Aachen, Germany.

${ }^{2}$ Institute of Heat and Mass Transfer, RWTH Aachen University, Aachen, Germany.

${ }^{3}$ Aachen-Maastricht Institute for Biobased Materials, Maastricht University at Chemelot Campus, Geleen, The Netherlands.

${ }^{4}$ Section for Pneumology, Department for Internal Medicine, RWTH Aachen University, Aachen, Germany.

(c) Anja Lena Thiebes et al. 2016; Published by Mary Ann Liebert, Inc. This Open Access article is distributed under the terms of the Creative Commons Attribution Noncommercial License (http://creativecommons.org/licenses/by-nc/4.0/) which permits any noncommercial use, distribution, and reproduction in any medium, provided the original author(s) and the source are credited.
} 


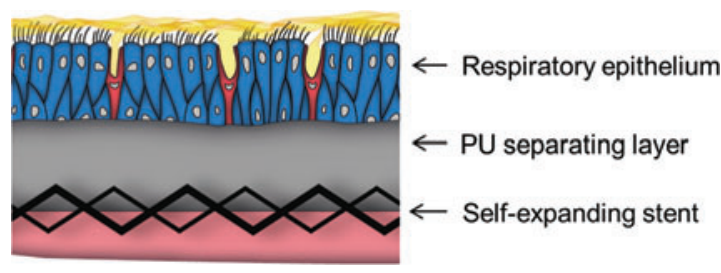

FIG. 1. PulmoStent concept. A metal stent with a nutrientpermeable cover is coated with respiratory epithelial cells for mucociliary clearance. Color images available online at www.liebertpub.com/tec

highly sensitive; crimping a cell seeded stent might harm the epithelial layer. To be able to coat the stent with epithelial cells in situ, we developed a novel and highly innovative method for flexible endoscopic spray application of cells.

Cell spraying was already described for different applications in vitro and in vivo. ${ }^{6-9}$ However, there are no reports on (flexible) endoscopic cell application. Previously, we could show that respiratory epithelial cells have a survival rate of almost $90 \%$ of the control after spraying with a commercially available fibrin glue nozzle and are able to differentiate with pseudostratified appearance and ciliogenesis in vitro. ${ }^{10}$ As adhesion layer, we used fibrin gel that was shown to be a suitable scaffold for respiratory epithelium ${ }^{11}$ and was already frequently used for spray application of cells. .,12,13 $^{-13}$

In this methodology article, we describe the setup for endoscopic spray application of respiratory epithelial cells, in vitro studies of cell behavior after spraying, and examinations of fluid dynamics of the system. Thus, we provide in-depth information on this new technology for the application of cells in tubular structures.

\section{Materials and Methods}

\section{Cell isolation and culture}

Ovine tracheae were harvested from sheep euthanized for other purposes at the Institute of Laboratory Animal Science in the University Hospital Aachen under sterile conditions and immediately placed in transport buffer (100 mM HEPES, $140 \mathrm{mM} \mathrm{NaCl}$ [Sigma-Aldrich], $2.5 \mathrm{mM} \mathrm{KCl}, 10 \mathrm{mM}$ glucose [both Merck], and 1\% antibiotic-antimycotic solution [ABM;
Gibco]; pH 7.4). The procedures used conform to the "Guide for the care and use of laboratory animals" published by the U.S. National Institutes of Health (The National Academies Press, 2011). Respiratory epithelial cells were isolated according to a protocol first published by Yamaya et al. ${ }^{14}$ In short, the mucosa was incised longitudinally, mucosa strips were removed and placed into a solution of $1.8 \mathrm{U} / \mathrm{mL}$ protease XIV (Sigma-Aldrich), and incubated at $4{ }^{\circ} \mathrm{C}$ overnight. After removal of the strips and centrifugation, the cells were dispersed in Dulbecco's modified Eagle's medium, seeded in cell culture flasks, and maintained in a humidified incubator at $37^{\circ} \mathrm{C}$ and $5 \% \mathrm{CO}_{2}$. After $48 \mathrm{~h}$, the medium was changed to Airway Epithelial Cell Growth Medium (PromoCell). When cells reached $70-80 \%$ confluence, cells were detached using $0.05 \%$ trypsin/ $0.02 \%$ EDTA solution (PAN-Biotech). Respiratory epithelial cells in passage 1 were used for this study.

\section{Spray setup}

To our knowledge, no device for spraying cells by flexible endoscopy exists. Thus, a new setup was developed, which allows spraying based on a clinically used bronchoscope and a commercially available catheter. This allows application of cells under visual control. The setup is shown in Figure 2. A doublelumen catheter is inserted in the working channel and sealed with a rubber leaflet valve. The catheter is carefully pushed forward until its end is $1.5 \mathrm{~mm}$ before the outlet of the working channel (Fig. 2B). Compressed air is connected to the working channel with a sterile filter in between. A pressure regulator and a gauge were used to achieve a fixed air pressure of $0.6 \mathrm{bar}$. The materials used for setup of the device are listed in Table 1.

With this system, cells can be administered endoscopically within a fibrin layer. Fibrinogen $(20 \mathrm{mg} / \mathrm{mL}$; Calbiochem $)$ and a polymerization solution $\left(7.5 \mathrm{mM}\right.$ Tris-buffered $\mathrm{CaCl}_{2}$ and 6 $\mathrm{IU} / \mathrm{mL}$ thrombin) are delivered separately via the respective lumens of the catheter and polymerize rapidly after spraying.

\section{Cell survival}

For all in vitro studies, the cell suspension was directly sprayed to the respective substrate (see below in this section and in "Cell differentiation.") with a distance of $1.5 \mathrm{~cm}$. As positive control we used a setup without airflow as described in Thiebes et al. ${ }^{10}$ As a second positive control, the
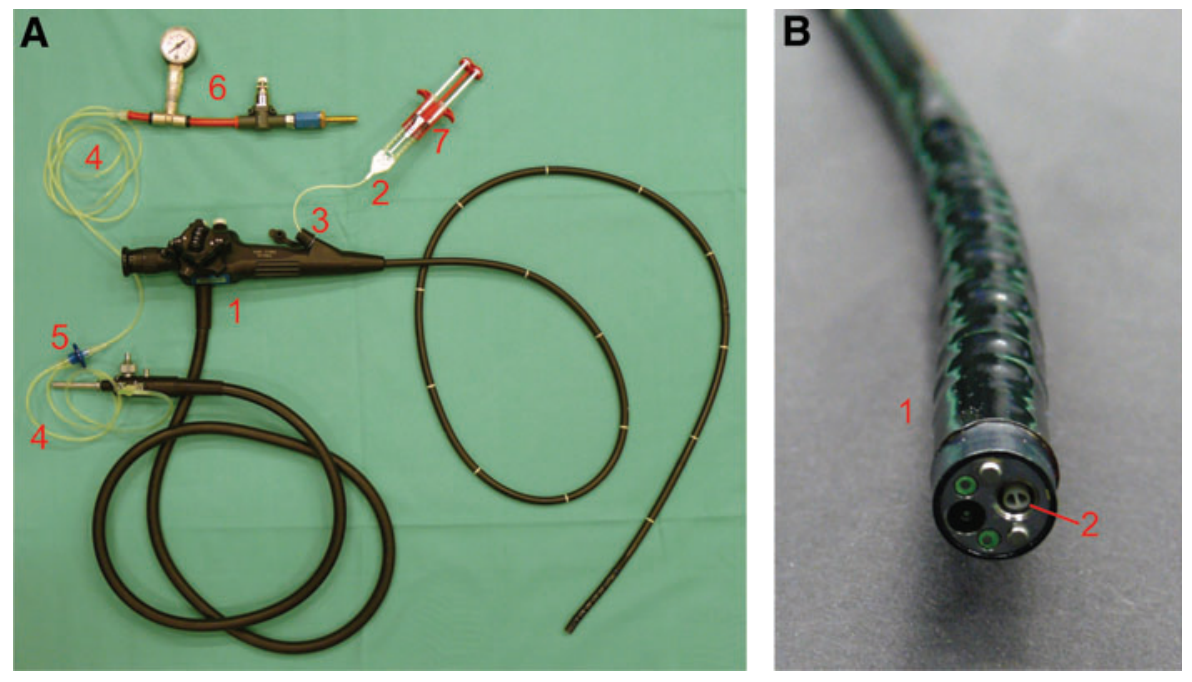

FIG. 2. Spraying setup. (A) Overview and (B) double-lumen catheter in working channel. (1) Bronchoscope, (2) catheter, (3) leaflet valve, (4) extension tubing, (5) sterile filter, (6) pressure gauge and regulator, and (7) syringe holder. Color images available online at www.liebertpub.com/tec 
Table 1. Material Used for the Spraying Setup

\begin{tabular}{|c|c|}
\hline Item & Company and specification \\
\hline Bronchoscope & 60512VG; Karl Storz \\
\hline Catheter & $\begin{array}{l}\text { Duplocath } 180 \text { Application Catheter; } \\
\text { Baxter }\end{array}$ \\
\hline \multicolumn{2}{|c|}{ Rubber leaflet valve 13991 DA; Karl Storz } \\
\hline Extension tubing & $\begin{array}{l}\text { 4097262, Heidelberger Verlängerung; } \\
\text { B. Braun AG }\end{array}$ \\
\hline Sterile filter & SLFG025LS, Millex; Merck Millipore \\
\hline $\begin{array}{l}\text { Pressure regulator } \\
\text { and gauge }\end{array}$ & 110.34 KD and 421.014-8; Riegler \\
\hline Syringe holder & Duploject sleeve; Baxter \\
\hline
\end{tabular}

bronchoscopy setup was used without airflow to see the general effect of flow through the catheter on the cells.

Live-dead staining was conducted with calcein AM (AAT Bioquest) and propidium iodide (PI; Sigma-Aldrich). Cells were counted with Neubauer chamber and resuspended in Dulbecco's phosphate buffered saline (Gibco). Living cells were stained with calcein AM $(4 \mu \mathrm{M})$, for $30-60 \mathrm{~min}$ at $37^{\circ} \mathrm{C}$. Then, $200 \mu \mathrm{L}$ cell suspension was sprayed to wells of a 12-well plate (CellStar; Greiner Bio-One) with a density of $8 \times 10^{4}$ cells $/ \mathrm{cm}^{2}$. After performing the spraying experiment, PI $(1 \mu \mathrm{g} / \mathrm{mL})$ was added to stain dead cells. The number of samples was five; from each sample five images were taken at distinct areas of the well. Images were acquired with a fluorescence microscope (Observer $\mathrm{Z1}$ and Axio Imager; Carl Zeiss) and a high resolution CCD camera (AxioCam MRC; Carl Zeiss).

For automated analysis, the images were processed with a self-written macro for counting particles in ImageJ (Version $1.44 \mathrm{p}$ ). All images were processed with the same parameters to ensure comparability.

\section{Statistical analysis}

Mean values and standard deviations were calculated for each parameter. Statistical significance between control and study groups was tested with an unpaired, two-tailed student's $t$-test in Microsoft Office Professional Plus 2010 Excel Version 14. A $p$-value above 0.05 was considered as not significant.

\section{Cell differentiation}

The differentiation experiments were accomplished under sterile conditions. For long-term culture, respiratory epithelial cells were directly sprayed onto three Transwell inserts (Corning) in a 12 well-plate with a density of $8 \times 10^{4}$ cells $/ \mathrm{cm}^{2}$. The insert membrane was precoated with collagen (from human placenta, Bornstein and Traub Type IV, $0.7 \mu \mathrm{g} / \mathrm{cm}^{2}$; Sigma-Aldrich). For experiments with fibrin gel, commercial fibrinogen and polymerization solution were prepared as previously described and cells resuspended in the polymerization solution. ${ }^{15}$ Fibrinogen and polymerization solution were drawn into separate syringes. For the experimental group without fibrinogen, the cell-medium suspension was applied with both syringes simultaneously.

Transepithelial electrical resistance was measured (Fig. 3 for average of all study groups, $n=1$ ). After 7 days of culture, air-liquid interface culture was established and a modified Airway Epithelial Cell Growth Medium with re-

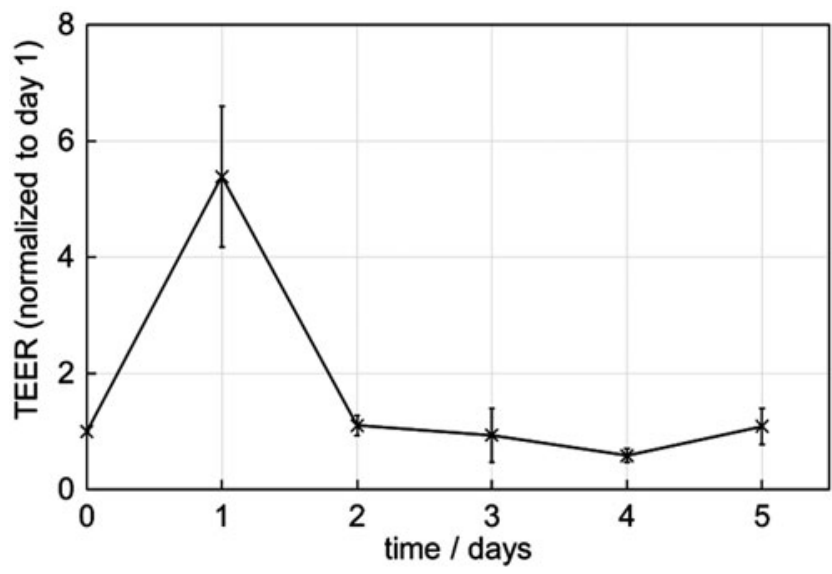

FIG. 3. Average transepithelial electrical resistance (TEER). Measured in one well of each study group.

tinoic acid was used (50 nM; Sigma-Aldrich; protocol from PromoCell). Medium was changed every other day.

\section{Histology and immunohistochemistry}

Preparation for histology, periodic acid Schiff's (PAS) reaction of paraffin sections and immunohistochemistry staining was conducted as described before by Cornelissen et al. ${ }^{11}$ In short, samples were fixed in Carnoy's fixative (60\% ethanol, $30 \%$ chloroform, and $10 \%$ acetic acid) for $30 \mathrm{~min}$ and dehydrated with increasing alcohol concentrations (TP1020-1; Leica) before embedding in paraffin. Samples were sectioned with $3 \mu \mathrm{m}$ thickness (Microtom Slide 2003, pfm Medical AG with blade S35, Feather) and stained with PAS by oxidation with periodic acid (Emsure; Merck), subsequent staining with Schiff's reagent (Merck) and counterstaining of the nuclei with hematoxylin (Sigma-Aldrich).

Samples for immunohistochemistry were stained with either anti-pan-cytokeratin (species: rabbit; Acris) with a concentration of 1:100 and Alexa Fluor-488 with a concentration of 1:400 (goat anti-rabbit IgG; Life Technologies) or anti-claudin-1 (species: rabbit; Biorbyt) with a concentration of 1:100 and Alexa Fluor-594 with a concentration of 1:400 (goat anti-rabbit IgG; Life Technologies).

\section{Scanning electron microscopy}

Electron microscopy was performed at the core facility for electron microscopy of the Medical Faculty of RWTH Aachen University. The cells were fixed in $3 \%$ glutaraldehyde, rinsed with sodium phosphate buffer (0.2 M, pH 7.39; Merck), and dehydrated consecutively in increasing acetone concentrations. The samples were critical-point dried in $\mathrm{CO}_{2}$, and sputter coated (Leica EM SC D500) with a $12.5 \mathrm{~nm}$ gold-palladium layer. Samples were analyzed using a scanning electron microscope (ESEM XL 30 FEG; FEI, Philips) with accelerating voltage of 7.5-10 kV (ESEM XL 30 FEG; FEI, Philips) in a high vacuum mode.

\section{Spraying in tubes}

To find out if the cells are distributed randomly when coating the lumen of a tube, a nearest neighbor analysis was conducted. ${ }^{16}$ The lumens of three $20 \mathrm{~mL}$ syringes (inner 
A conventional photography

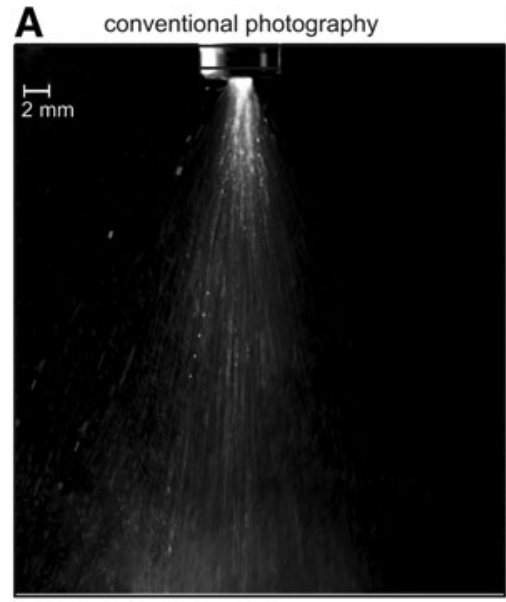

B

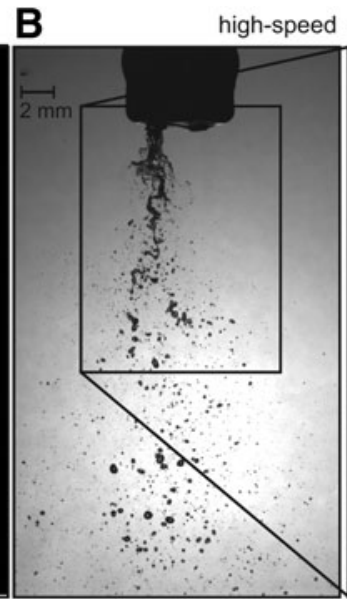

diameter: $20 \mathrm{~mm}$; BD Medical) were covered with a piece of paper, which was subsequently coated with cells by slowly moving the bronchoscope tip inside the syringe. We used vascular smooth muscle cells that were stained with calcein AM before spraying (isolation and culture was described by Tschoeke et $a l .{ }^{17}$ ). Immediately after the spray process, the paper was removed from the syringe and cut lengthwise. A tile image of the calcein-stained cells on the paper was taken with Zeiss Zoom.V16 and ZEN pro software (2012, blue edition). To analyze the cell distribution, all images that showed the sample were analyzed with the process Find Maxima and Analyze Particles with ImageJ (Version 1.47v). The average distance of the nearest neighbor (NN) was calculated with the Nearest Neighbor Distances-plugin (programmed by Yuxiong Mao) and the following formulas in Microsoft Office Professional Plus 2010 Excel Version 14:

$$
\begin{gathered}
N N_{\text {Expected }}=\frac{1}{2} * \sqrt{\frac{\text { area }}{\text { counted cells }}} \\
N N \text { Index }=\frac{\text { AvgNN }}{\text { ExpectedNN }}
\end{gathered}
$$

The Nearest Neighbor Index is the ratio between the measured average distance between two neighboring cells and the expected distance for random distribution. It allows a statement on whether the particles are distributed randomly or not. It ranges between 0 and 2.1419; if it is close to 0 , the particles are clustered, if it is around 1, they are distributed randomly and if it is close to 2.1419 , the particles are arranged in a uniform way. ${ }^{18}$

\section{Fluid dynamic analysis}

Different visualization methods can be used to capture images of a propagating spray. For the spray of this study, conventional photography is less suitable due to the high fluid velocity (Fig. 4). Therefore, high-speed imaging was applied to guarantee sharp images without motion blur.

A continuous xenon-arc lamp was used for diffusive background illumination. A macro objective provides the required magnification of the spray phenomenon. The recorded highspeed video consists of 200 single images that show the steady state propagation of the spray. The total length of the video was
13.33 ms (Supplementary Video S1; Supplementary Data are available online at www.liebertpub.com/tec). Table 2 summarizes the optical setup.

The recorded video was postprocessed with a selfdeveloped algorithm that was implemented in MATLAB. Each image of the video was analyzed in the same way:

(1) Fourier filtering: Inhomogeneous illumination (Fig. 4B, C) of the images was removed using a fast Fourier filtering by frequencies/types of structures. ${ }^{19}$

(2) Binarization: The grayscale image was binarized for later object tracking. The threshold for binarization was fixed to $15 \%$. This value results from a sensitivity analysis that guarantees independence of the binarization threshold from background noise, that is, each detected structure represents liquid.

(3) Structure tracking: Figure 5A shows an image with its tracked structures, each characterized by its area, position, and equivalent diameter. ${ }^{20}$ Based on this method all droplets (even the smallest) are taken into account. Due to the limited resolution of the optical setup, the determination of diameters of smallest droplets is limited by the image scale to $44.8 \mu \mathrm{m}$ (length of one pixel), that is, smaller droplets are also assigned to this first droplet size class.

Then, images were further interpreted on microscopic and macroscopic level: The distribution of droplet area (pixel area) was determined and further used to calculate the distribution of equivalent droplet diameters. Furthermore, a mean droplet diameter $\mathrm{D}_{10}$ was defined as the equivalent diameter of the arithmetic mean droplet area. Additionally, spray was characterized on macroscopic scale by its cone

Table 2. Parameters of the Optical Setup

\begin{tabular}{ll}
\hline Optical parameter & \multicolumn{1}{c}{ Value } \\
\hline Light source & Continuous xenon-arc white light \\
Camera & Photron FastCam SAx, 8 bit \\
Camera lens & Zeiss Macro Planar T100 f/2 \\
Frame rate & $15,000 \mathrm{fps}$ \\
Shutter speed & $2.5 \mu \mathrm{s}$ \\
Image size & $1024 \times 848$ pixels \\
Scale & 22.322 pixels $/ \mathrm{mm}$ \\
Magnification & 0.448 \\
\hline
\end{tabular}


FIG. 5. Analyzed spray images. (A) Shows a single shot of the high-speed visualization after image postprocessing. Structures that were tracked by the algorithm are highlighted by a circle that corresponds to the equivalent diameter of the object. (B) Shows the cumulated sum of all images after Fourier filtering (step 1) supplemented by the steady state cone angle and tube wall position. Color images available online at www.liebertpub.com/tec
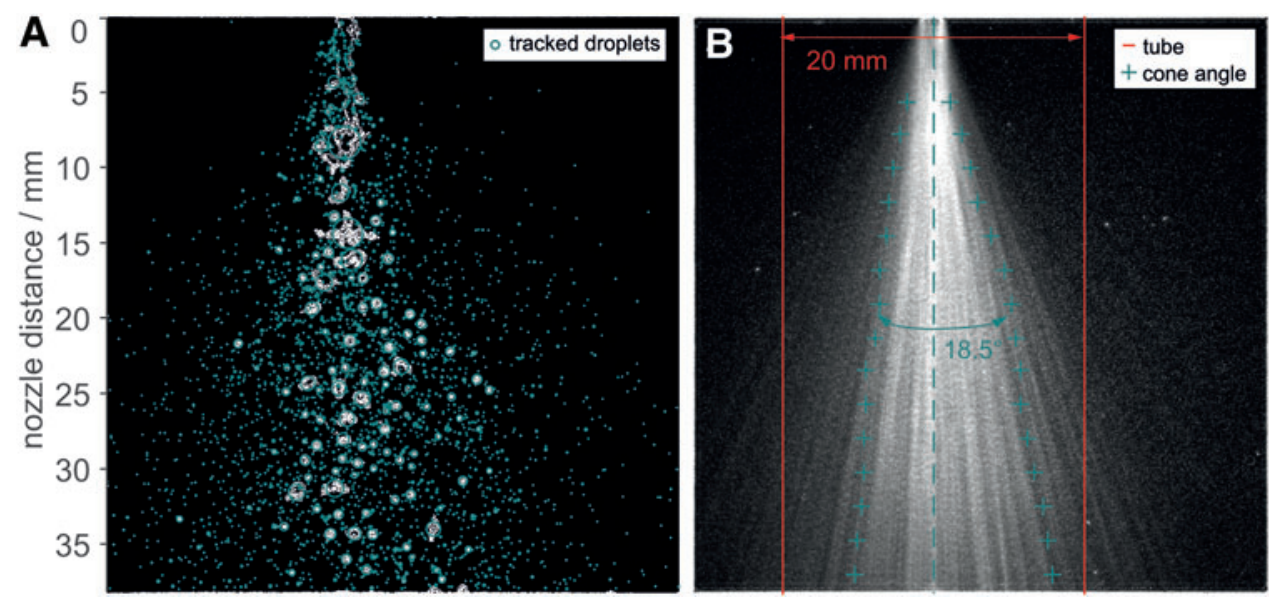

angle. At last, a virtual boarder was defined that represents the tube wall. This virtual wall was used for analyzing the mass fraction, size, and velocity of droplets that would coat the given stent (Fig. 5B).

\section{Results and Discussion}

In a first experiment, we measured the cell survival rate directly after spraying with the endoscopic system and after administering the cells through the catheter without compressed air. As a positive control, a nonsprayed cell suspension was analyzed. The results can be seen in Figure 6: with values of $99.9 \%$ and $98.5 \%$, respectively, no significant influence on the survival rate can be found.

This is especially interesting as in a previous study, we found a significant reduction of cell viability after spraying with a commercially available fibrin spray nozzle (Tisseel Easyspray set; Baxter) by $11.5 \% .^{10}$ In general, the setup of the nozzle is similar: a core consisting of two outlets for the cell suspension and compressed air flowing out around. However, even small changes in dimension of the nozzle and air velocity can influence the spray and thus shear and elongation stresses acting on the cells. ${ }^{21}$ The outlet area of the air flow around the catheter might have an important

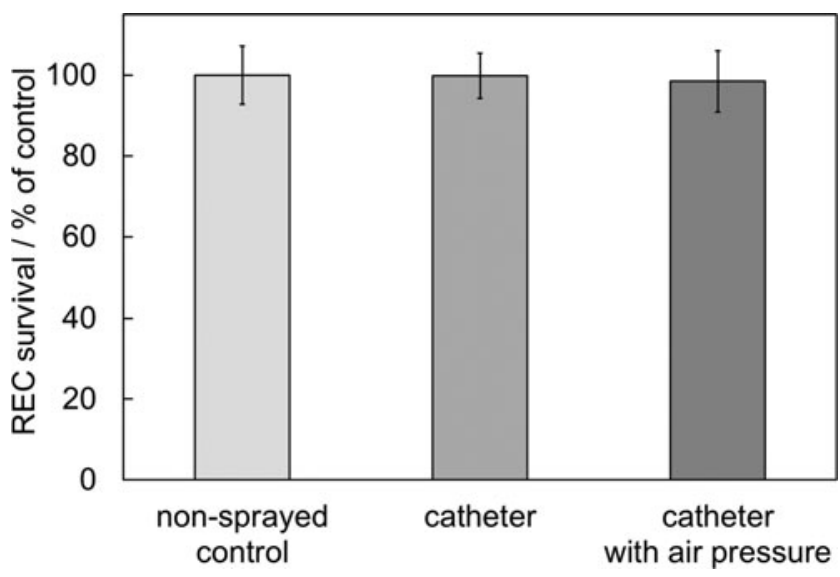

FIG. 6. Cell survival when applied and sprayed with catheter. Application and spraying of respiratory epithelial cells with a catheter does not influence the survival rate. Error bars indicate standard deviation. No significance to control with $p<0.05$. REC, respiratory epithelial cells. impact as it directly influences the air velocity. Hence, the geometry of the new endoscopic spraying device appears to favor cell survival compared to the previously used spray nozzle although the cells have to pass a much longer distance through the catheter.

When evaluating whether the spraying process has an influence on respiratory epithelial cells, testing their differentiation capacity afterward is highly important. Here, we added a study group in which the cells were sprayed in fibrin gel to prove that adding fibrin gel as adhesion layer does not have an influence on differentiation. The results of the differentiation experiment are shown in Figure 7 , the nonsprayed control in the left, sprayed cells in the middle, and cells sprayed within fibrin gel in the right column.

Figure 7A-F depicts sections stained by PAS, Figure 7G-I shows scanning electron microscopy images. In all groups, a pseudostratified appearance with columnar-shaped cells is seen with basal cells on the lower side. Apically, there are ciliated cells (arrows) and goblet cells (arrowheads) present. The cilia can also be seen in the electron microscopy images. Figure 7J-O shows immunohistochemistry stainings of the respective groups. Figure $7 \mathrm{~J}-\mathrm{L}$ shows uniform pancytokeratin expression in all groups. Figure $7 \mathrm{M}-\mathrm{O}$ shows uniform expression of Claudin-1. Claudin-1 is a protein of tight junctions that proves the barrier function of the epithelial layer. This shows that long-term differentiation capacity is neither influenced by application with the endoscopic spray device nor by embedding them in a fibrin gel spray with the same setup. The respective native controls can be seen in the Supplementary Figure S1. Interestingly, in our previous study, the fibrin gel appeared to slow the process of differentiation and ciliogenesis. As the new setup also has a higher survival rate, this could have an influence on the speed of differentiation: If more cells survive the application process, the cells form a confluent layer more rapidly and hence start the differentiation process earlier.

In addition to the in vitro studies in wells as described above, we tested the device for covering the lumen of tubular structures. As a simple setup, the lumen of a syringe was covered with paper and coated with calcein-stained cells. To visualize the cells, the paper could be easily removed from the syringe and cut lengthwise to unfold the lumen. The calceinstained cells were then analyzed for random distribution on the paper by nearest-neighbor analysis. 

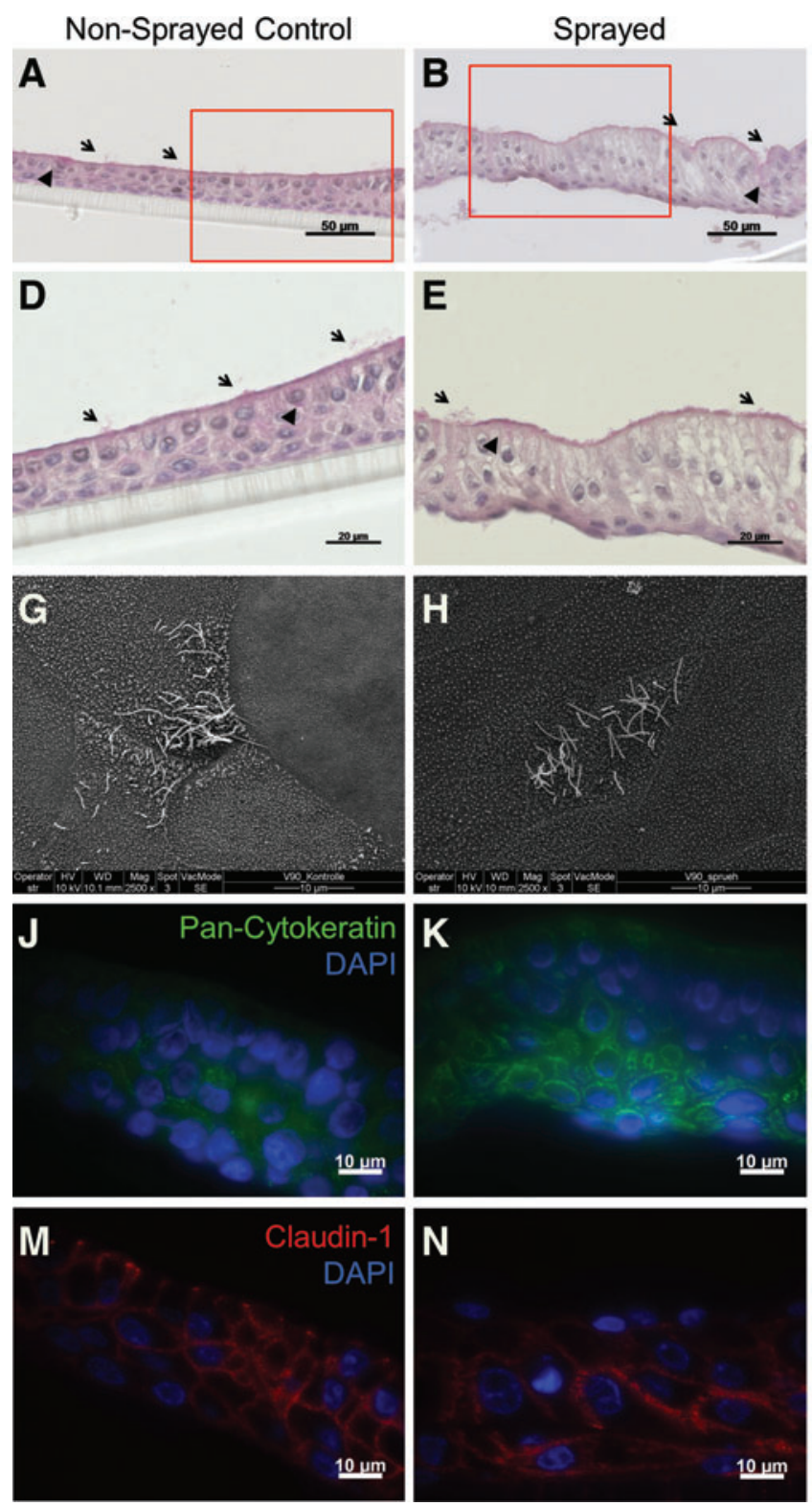

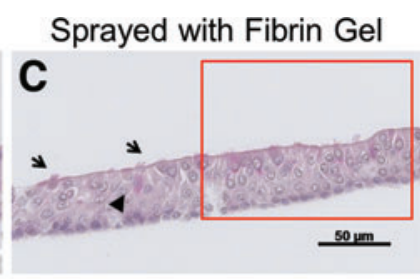

$\mathbf{F}$
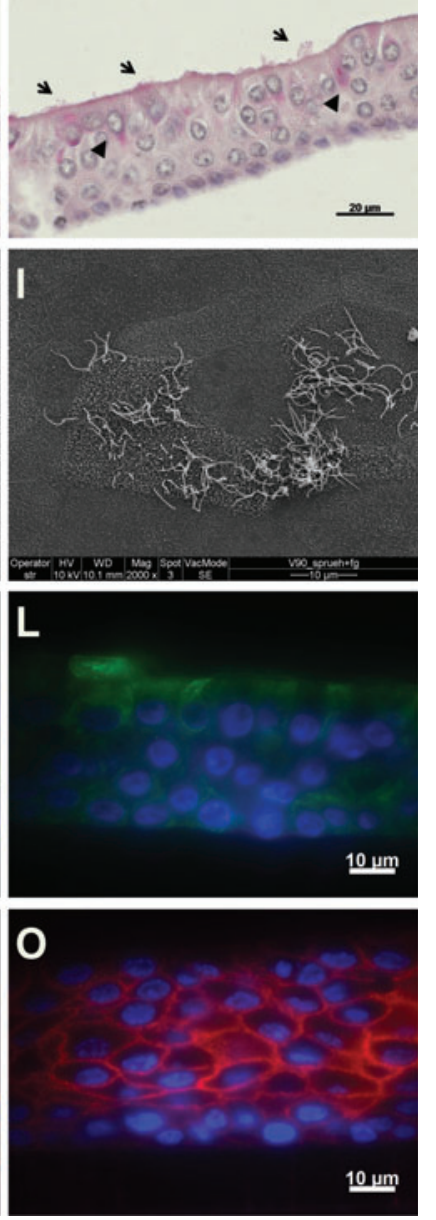

FIG. 7. Long-term differentiation of respiratory epithelial cells. Nonsprayed control (A, D, G, J, M), cells after spray application without $(\mathbf{B}, \mathbf{E}, \mathbf{H}, \mathbf{K}, \mathbf{N})$ and with fibrin gel $(\mathbf{C}, \mathbf{F}, \mathbf{I}, \mathbf{L}, \mathbf{O})$. (A-F)

Periodic acid Schiff's reaction; (D-F) show magnifications of (A-C). Epithelial cells show a columnar shape with cilia on all samples (arrows); goblet cells can also be seen (arrowheads). (G-I) Scanning electron microscopy images show cilia on cell surface in all samples. ( J-O) Immunohistochemistry of pancytokeratin ( $\mathbf{J}-\mathbf{L})$ and claudin1 (M-O) show uniform expression of the epithelial marker and tight junction proteins, respectively. Color images available online at www .liebertpub.com/tec
The nearest-neighbor index of all samples is 1.2 with a range of 1.10-1.31. As the value is higher than 1, it displays that the cells are not clustered and the endoscopic spraying device allows coating of tubular constructs with cells with homogeneous distribution.

To conclude, a high survival rate and a random distribution of cells are achieved using the novel endoscopic spray setup. Both parameters indicate a good applicability of this nozzle for future implant covering. Experimental verification of this conclusion was done based on a microscopic and macroscopic study of the endoscopic spray using water as surrogate (Fig. 5).

In a first step, droplets were extracted from binarized images and characterized by their size, resulting in a relative density function and a relative cumulative distribution of droplet area and droplet diameters (Fig. 8). Size bins are equally spaced for droplet area (Fig. 8A) but show a decreasing width for droplet diameters (Fig. 8C), since droplet diameters result from a square root function of droplet areas.
Due to this effect the mean droplet diameter is determined using the mean arithmetic droplet area.

It is shown that the majority of droplets has a diameter much larger than respiratory epithelial cells (typical size: $<20 \mu \mathrm{m}$ ) with a mean diameter of $\mathrm{D}_{10}=161.9 \mu \mathrm{m}$. Therefore, no significant influence of droplet formation on cell survival rates is expected, which is consistent with the high values of survival rates $(98.5 \%)$ found before. However, there is still potential for improvements: The resulting spray has a polydisperse character, which might not facilitate a homogeneous covering of implants. Future work should aim at a more monodisperse spray. Moreover, sizes of many droplets (about 50\%) are in the range of the smallest detectable liquid structures. Therefore, future investigations should aim for a higher image resolution.

Spatial variations of droplet sizes and local mass flows were neglected based on the global spray characterization in Figure 8. As shown in Figure 9, this simplification could be misleading, because droplet sizes vary significantly over spray 
FIG. 8. Relative density and cumulative distribution of droplet area $(\mathbf{A}, \mathbf{B})$ and droplet diameters $(\mathbf{C}, \mathbf{D})$ of the endoscopic spray. Values are based on the analysis von 200 consecutive images of the high-speed visualization. The mean droplet diameter accounts for $\mathrm{D}_{10}=161.9 \mu \mathrm{m}$. Color images available online at www.liebertpub .com/tec
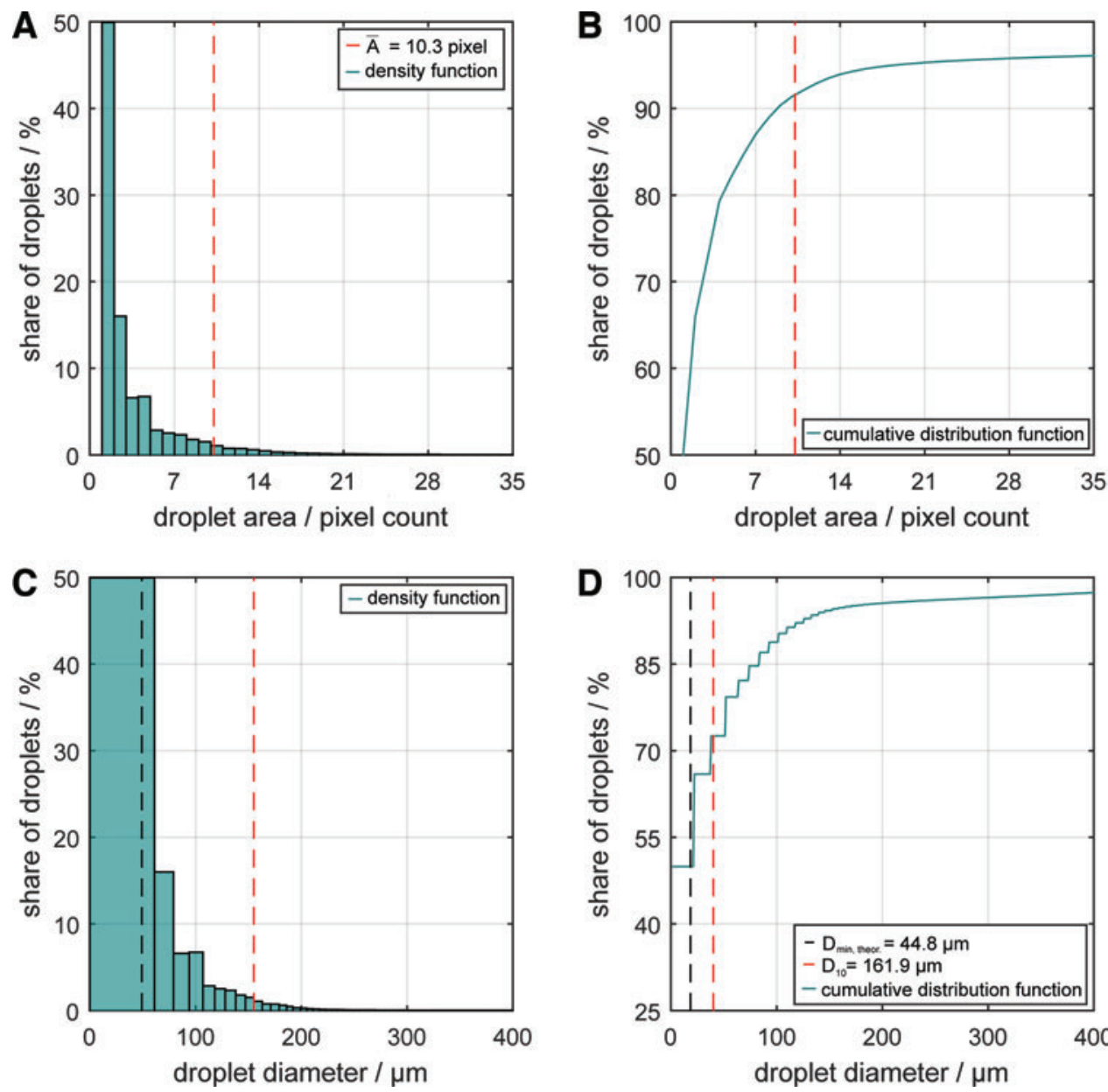

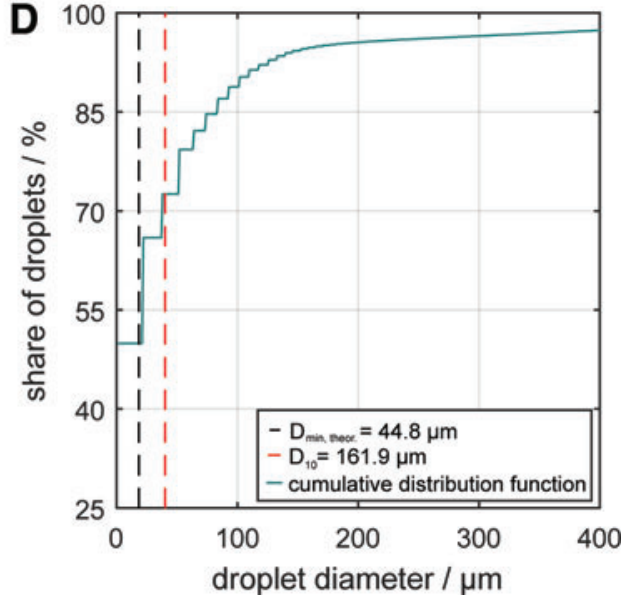

radius: large droplets are mainly found on the spray axis, small droplets mainly at the spray edge. This important spray characteristic has a direct impact on the covering process in hollow organs or tubes. If tube walls are orientated parallel to the jet axis, the covering process will be mostly determined by the spray edge (and therefore mainly by small droplets).
This is confirmed by Figure 10, showing the mass fraction coating the wall (Fig. 10A) and the arithmetic mean diameter $\mathrm{D}_{10}$ of impacting droplets (Fig. 10B), each as a function of nozzle distance. Due to the fact that spray characterization in Figure 10 was done without any tube but in free flow, transferability of results is only allowed on the basis of two
FIG. 9. Distribution of arithmetic mean diameter over 200 analyzed spray images. The image highlights the predominant travel direction of the single droplets. Color images available online at www.liebertpub.com/tec

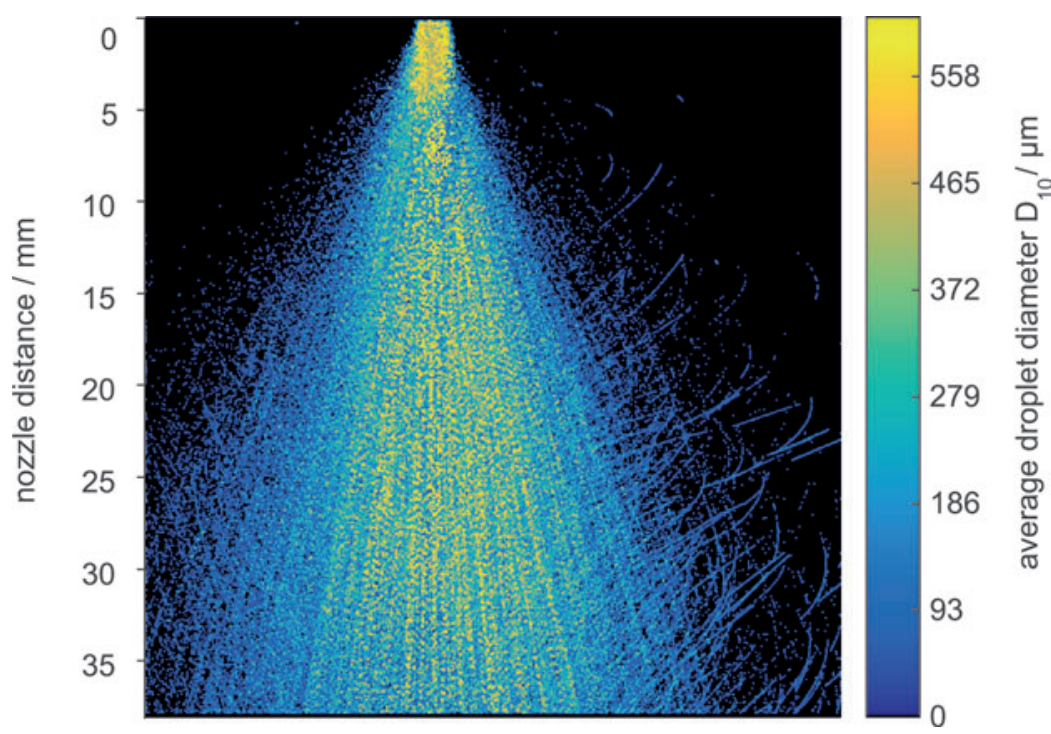



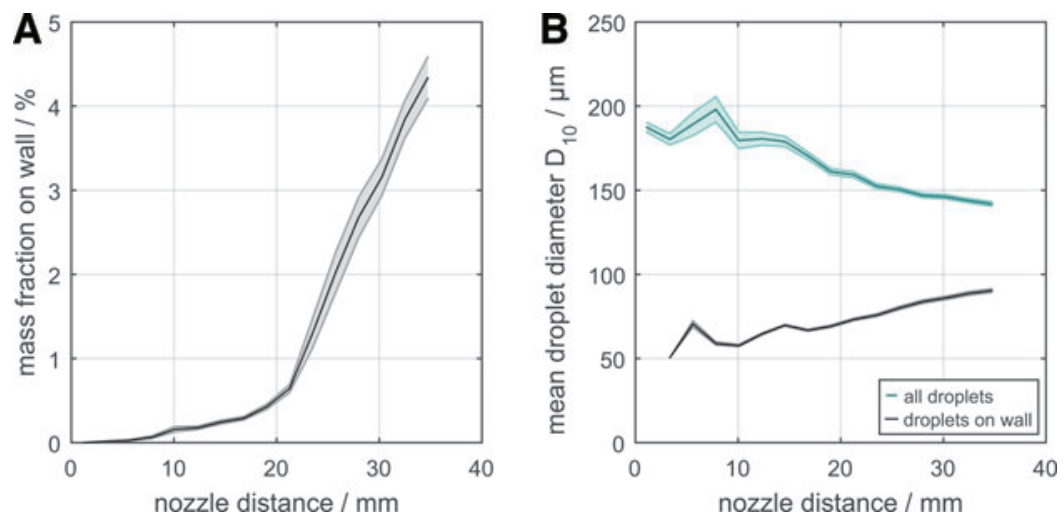

FIG. 10. Analysis of spray coating a stent with a diameter of $20 \mathrm{~mm}$. (A) Mass distribution of droplets coating the tube and (B) corresponding droplet size distribution for the total spray and spray-wall interaction. Color images available online at www .liebertpub.com/tec

main assumptions: (1) the tube wall does not significantly influence droplet's trajectories close to the wall, (2) droplets remain (are stuck) at the tube wall, once hitting it (bouncing and splashing are neglected).

Based on Figure 10A it is found that with this setup only a small mass fraction hits the wall (up to $4 \%$ ) inside the given nozzle distance range, because the predominant mass fraction (the large droplets) is located on the spray axis (Fig. 9). Even though hitting droplets are comparatively small-sized, they are still larger than cells and a sufficiently high survival rate is guaranteed (Fig. 10B). The mass fraction hitting the wall can be easily increased by moving the tip of the flexible endoscope toward the wall and thus allowing also the larger droplets to hit it.

With a high survival rate, differentiating respiratory epithelial cells and randomly distributed cells in coated tubes, we present a novel and effective device for spray application of cells into tubular implants. Such implants could be stents or full prostheses. Especially for airway stents this flexible endoscopic method appears to be highly promising and essential as a layer of respiratory epithelial cells on a stent would probably not withstand the process of crimping and deployment.

Not only stents or other tubular implants can be coated with cells with our device, but also the field of cell therapy could benefit significantly. A recent study by Feizpour et al. in guinea pig has shown that intratracheal administration of adipose-derived stromal cells can improve biochemical parameters and blood cells counts in chronic obstructive pulmonary disease; differential white blood cell counts were restored, interleukin- 8 concentration and broncho-alveolar lavage fluid improved compared with intravenous administration. ${ }^{22}$ Similar results have been obtained by Curley et al. in treatment of ventilator-induced lung injury in rats. ${ }^{23}$ Intratracheal administration of mesenchymal stromal cells increased the repair in terms of higher arterial oxygenation, lower inflammation, and histologic injury compared with a nontreated control. When comparing intratracheal and intravenous administration, the improvements were comparable but more mesenchymal stromal cells were retained in the lung when administered intratracheally.

To administer cells in a human or large animal lung, using our endoscopic spraying device is highly feasible. When embedding the cells in fibrin gel, a very limited amount of liquid is needed, thus preventing instillation of too much liquid that further harms the lung. $\mathrm{O}_{2}$ can be used in this case as compressed air.
Nevertheless, the spraying device can be used not only in the respiratory system, but basically in all tubular/hollow organs like, for example, the gastrointestinal (GI) tract. As described by Flores et al. cell therapy with different cell types is feasible in inflammatory bowel disease. ${ }^{24}$ With the spray administration of the respective cells, cell migration and homing is not a critical factor anymore. In the latter application, using compressed $\mathrm{CO}_{2}$ to spray the cells has the advantage that it is tissue-absorbable and thus causing less flatulence in the GI tract. ${ }^{25}$ Depending on the application different endoscopes (bronchoscope, gastroscope, and colonoscope) have to be used. As all medical endoscopes have a working channel, the catheter for the spray application can be inserted. For the GI-tract, that is, the large intestine, a major difficulty will be sacculation of the mucosa that complicates coating the entire surface. The cell type and number is always dependent on application and disease. Navarro et al. demonstrated that the distance of the nozzle to the substrate is important and can have an influence on cell survival. ${ }^{26}$ Thus, for new applications, this influence should be tested when seeding cells into tubes of different diameters.

Similarly, the application of endothelial cells onto implants, stents, or tissue-engineered constructs for the cardiovascular system is a highly promising option for our device. This can prevent thrombogenicity of the implants. ${ }^{27}$ In the case of cardiovascular application, there might be some modifications necessary to reduce the outer diameter of the system and due to the risk of embolus formation in situ application might not be feasible. Nevertheless, the setup can also be used for in vitro application of endothelial cells before implantation.

\section{Conclusions}

We present here a novel and easy setup for spraying cells in a liquid or a two-component hydrogel endoscopically into tubular structures. With the setup cells can be applied under visual control. It is based on a conventional bronchoscope combined with a double-lumen catheter and compressed air. The system was evaluated by spray application of respiratory epithelial cells, which show unchanged survival rate and differentiation after long-term culture. To be able to fully understand the processes when spraying cells with our device we also analyzed its fluid dynamics and found droplet sizes mainly larger than cells, which can explain the high survival rate. However, the mass fraction of droplets 
hitting stent or tube walls is still relatively low when adjusting the endoscope tip parallel to the walls. Other nozzle designs might be more feasible for this application and will be investigated in future.

The setup can be used not only in the respiratory system but for covering tubular implants or stents with cells in any organ or for administration of cells to various hollow organs as cell therapy. Thus, this device for spray application of cells promises a good survival rate and even distribution of cells in a variety of different applications.

\section{Acknowledgments}

This work was funded by the European Union's Seventh Framework Programme (FP7/2007-2013 under Grant agreement No. NMP3-SL-2012-280915), a grant from the START program of the Medical Faculty of RWTH Aachen University and the Excellence Initiative of the German federal and state governments. We thank the Institute of Laboratory Animal Science of the RWTH Aachen University Hospital headed by Univ.-Prof. Dr. med. René H. Tolba and especially Ms. Lisa Liebenstund and Mr. Thaddäus Stopinski for their excellent help with the animal material.

\section{Disclosure Statement}

No competing financial interests exist.

\section{References}

1. Yataco, J.C., and Mehta, A.C. Upper airway obstruction. In: Raoof, S., George, L., Saleh, A., and Sung, A., eds. ACP Manual of Critical Care, 1st ed. New York: McGraw Hill Medical, 2009, pp. 388-397.

2. Dutau, H., Musani, A.I., Plojoux, J., Laroumagne, S., and Astoul, P. The use of self-expandable metallic stents in the airways in the adult population. Expert Rev Respir Med 8, 179, 2014.

3. Chin, C.S., Litle, V., Yun, J., Weiser, T., and Swanson, S.J. Airway stents. Ann Thorac Surg 85, S792, 2008.

4. Weinandy, S., Rongen, L., Schreiber, F., Cornelissen, C., Flanagan, T.C., Mahnken, A., Gries, T., Schmitz-Rode, T., and Jockenhoevel, S. The biostent: novel concept for a viable stent structure. Tissue Eng Part A 18, 1818, 2012.

5. Jockenhoevel, S., Deichmann, T., Gries, T., Schmitz-Rode, T., Mahnken, A., and Weinandy, S. Patent: implant, method for producing such an implant, and use. 2011.

6. Bahoric, A., Harrop, A.R., Clarke, H.M., and Zuker, R.M. Aerosol vehicle for delivery of epidermal cells - an in vitro study. Plastic Surg 5, 153, 1997.

7. Cohen, M., Bahoric, A., and Clarke, H.M. Aerosolization of epidermal cells with fibrin glue for the epithelialization of porcine wounds with unfavorable topography. Plast Reconstr Surg 107, 1208, 2001.

8. Veazey, W.S., Anusavice, K.J., and Moore, K. Mammalian cell delivery via aerosol deposition. J Biomed Mater Res B Appl Biomater 72, 334, 2005.

9. Zimmerlin, L., Rubin, J.P., Pfeifer, M.E., Moore, L.R., Donnenberg, V.S., and Donnenberg, A.D. Human adipose stromal vascular cell delivery in a fibrin spray. Cytotherapy 15, 102, 2013.

10. Thiebes, A.L., Albers, S., Klopsch, C., Jockenhoevel, S., and Cornelissen, C.G. Spraying respiratory epithelial cells to coat tissue engineered constructs. Biores Open Access 4, 278, 2015.
11. Cornelissen, C.G., Dietrich, M., Kruger, S., Spillner, J., Schmitz-Rode, T., and Jockenhoevel, S. Fibrin gel as alternative scaffold for respiratory tissue engineering. Ann Biomed Eng 40, 679, 2012.

12. Kaminski, A., Klopsch, C., Mark, P., Yerebakan, C., Donndorf, P., Gabel, R., Eisert, F., Hasken, S., Kreitz, S., Glass, A., Jockenhovel, S., Ma, N., Kundt, G., Liebold, A., and Steinhoff, G. Autologous valve replacement-cd133+ stem cell-plus-fibrin composite-based sprayed cell seeding for intraoperative heart valve tissue engineering. Tissue Eng Part C Methods 17, 299, 2011.

13. Falanga, V., Iwamoto, S., Chartier, M., Yufit, T., Butmarc, J., Kouttab, N., Shrayer, D., and Carson, P. Autologous bone marrow-derived cultured mesenchymal stem cells delivered in a fibrin spray accelerate healing in murine and human cutaneous wounds. Tissue Eng 13, 1299, 2007.

14. Yamaya, M., Finkbeiner, W.E., Chun, S.Y., and Widdicombe, J.H. Differentiated structure and function of cultures from human tracheal epithelium. Am J Physiol 262, L713, 1992.

15. Flanagan, T.C., Cornelissen, C., Koch, S., Tschoeke, B., Sachweh, J.S., Schmitz-Rode, T., and Jockenhoevel, S. The in vitro development of autologous fibrin-based tissueengineered heart valves through optimised dynamic conditioning. Biomaterials 28, 3388, 2007.

16. Lu, C., Almeida, J.M.P., Yao, N., and Arnold, C. Fabrication of uniformly dispersed nanoparticle-doped chalcogenide glass. Appl Phys Lett 105, 261906, 2014.

17. Tschoeke, B., Flanagan, T.C., Koch, S., Harwoko, M.S., Deichmann, T., Ella, V., Sachweh, J.S., Kellomaki, M., Gries, T., Schmitz-Rode, T., and Jockenhoevel, S. Tissueengineered small-caliber vascular graft based on a novel biodegradable composite fibrin-polylactide scaffold. Tissue Eng Part A 15, 1909, 2009.

18. Clark, P.J., and Evans, F.C. Distance to nearest neighbor as a measure of spatial relationships in populations. Ecology 35, 445, 1954.

19. Palmer, J., Ramesh, M., Kirsch, V., Reddemann, M., and Kneer, R. Spray analysis of c8h18o fuel blends using highspeed schlieren imaging and mie scattering. Presented at the 12th International Conference on Engines \& Vehicles (ICE), Capri, Italy, 2015.

20. Reddemann, M.A., Kirsch, V., and Kneer, R. Transmitted light microscopy of primary breakup for engine-relevant ambient densities. Presented at the 26th European Conference Liquid Atomization and Spray Systems (ILASS), Bremen, Germany, 2014.

21. Duncan, C.O., Shelton, R.M., Navsaria, H., Balderson, D.S., Papini, R.P., and Barralet, J.E. In vitro transfer of keratinocytes: comparison of transfer from fibrin membrane and delivery by aerosol spray. J Biomed Mater Res B Appl Biomater 73, 221, 2005.

22. Feizpour, A., Boskabady, M.H., and Ghorbani, A. Adiposederived stromal cell therapy affects lung inflammation and tracheal responsiveness in guinea pig model of COPD. PloS One 9, e108974, 2014.

23. Curley, G.F., Ansari, B., Hayes, M., Devaney, J., Masterson, C., Ryan, A., Barry, F., O’Brien, T., Toole, D.O., and Laffey, J.G. Effects of intratracheal mesenchymal stromal cell therapy during recovery and resolution after ventilator-induced lung injury. Anesthesiology 118, 924, 2013.

24. Flores, A.I., Gomez-Gomez, G.J., Masedo-Gonzalez, A., and Martinez-Montiel, M.P. Stem cell therapy in inflam- 
matory bowel disease: a promising therapeutic strategy? World J Stem Cells 7, 343, 2015.

25. $\mathrm{Wu}, \mathrm{J}$., and $\mathrm{Hu}, \mathrm{B}$. The role of carbon dioxide insufflation in colonoscopy: a systematic review and meta-analysis. Endoscopy 44, 128, 2012.

26. Navarro, F.A., Stoner, M.L., Park, C.S., Huertas, J.C., Lee, H.B., Wood, F.M., and Orgill, D.P. Sprayed keratinocyte suspensions accelerate epidermal coverage in a porcine microwound model. J Burn Care Rehabil 21, 513, 2000.

27. Avci-Adali, M., Ziemer, G., and Wendel, H.P. Induction of EPC homing on biofunctionalized vascular grafts for rapid in vivo self-endothelialization - a review of current strategies. Biotechnol Adv 28, 119, 2010.
Address correspondence to: Stefan Jockenhoevel, Univ-Prof Dr Med Department of Tissue Engineering and Textile Implants Institute of Applied Medical Engineering Helmholtz Institute RWTH Aachen University Pauwelsstraße 20 52074 Aachen

Germany

E-mail: jockenhoevel@ame.rwth-aachen.de

Received: August 19, 2015

Accepted: December 18, 2015

Online Publication Date: March 7, 2016 